\title{
A Study on Measurement of Light Tar Content in the Fuel Gas Produced in Small-Scale Gasification and Power Generation Systems for Solid Wastes"
}

\author{
Young-il SON ${ }^{* *}$, Masayuki SATO**, Tomoaki NAMIOKA ${ }^{* *}$ \\ and Kunio YOSIKAWA ${ }^{* *}$ \\ ${ }^{* *}$ Department of Environmental Science and Technology, Tokyo Institute of Technology, \\ 4259, Nagatsuta, Midori-ku, Yokohama 226-8502, Japan \\ E-mail : sonyi@kier.re.kr
}

\begin{abstract}
We have been developing small-scale gasification and power generation systems utilizing solid wastes. These systems employ dual-fueled diesel engines, which do not accept condensable tar content in the produced fuel gas. This paper describes a newly developed measurement method for small amount of light-weight tar (light tar) content in the fuel gas in a short time which is appropriate for usage in commercial plants. Furthermore, by employing this measurement method, the technical feasibility of removal of the light tar content in the fuel gas was showed by utilizing sawdust filter or activated carbon filter in the laboratory scale experiment and in the commercial plant.
\end{abstract}

Key words: Gasification, Power Generation, Light Tar, Measuring Method

\section{Introduction}

We have been working on research and development of a small-scale gasification power generation system. Built in 2004, a 1ton/hr waste gasification power generation plant, fed with municipal solid waste (MSW) and meat bone meal, is being run in a community with a population of roughly 7,000. ${ }^{[1]}$ This plant has successfully produced fuel gas with required level of the calorific value. But in the course of the power generation process, some condensates have been accumulated on the surface of a turbocharger impeller within the engine and elsewhere as the fuel gas is cooled by adiabatic expansion while it passes through the pressure reducing valve. An analysis of the condensates indicates that approximately $60 \%$ of the total mass is ammonium chloride, about $30 \%$ is light tar with relatively higher vapor pressure, and the remainder is heavy tar with relatively lower vapor pressure. Such cases have often been reported in previous studies on waste gasification power generation plants, but the concentration of tar within fuel gas permissible for internal combustion engines has not yet been clarified. ${ }^{[2-4]}$ In the case of heavy tar, which consists of substances with relatively lower vapor pressure, it is possible to decompose and remove it with the reformer and cooling/gas cleaning facilities installed in this plant. Light tar, whose main ingredients have relatively higher vapor pressure, however, cannot be removed in existing facilities and could flow into the engine along with fuel gas. For this reason, in this study, small amount of light-weight tar, which is believed to be comprised mainly of components with relatively higher vapor pressure in the fuel gas, is defined as light tar and a method for measuring it is suggested. Using the proposed method of measurement, light tar in this commercial plant is analyzed and possible methods for removing it are examined.

*Received 10 Dec., 2008 (No. T1-06-1157) Japanese Original : Trans. Jpn. Soc. Mech. Eng., Vol.73, No.730, B (2007),

pp.1399-1405 (Received 21 Nov., 2006) [DOI: 10.1299/jee.4.12] 


\section{Method for Measuring Light Tar}

\subsection{Sampling method}

Tar collection methods are divided into dry and wet methods. A typical example of wet methods is to dissolve tar in a solvent contained in an impinger bottle and to measure its mass. ${ }^{[5]}$ In this case, the sampling process takes a long time and involves vaporization loss, transportation regulations, and other issues as the solvent has many volatile ingredients. Therefore, the wet methods are considered to be inadequate for measurement in a commercial plant. As for dry methods, the solid phase absorption (SPA) method is recommended by the Biomass Technology Group (BTG). ${ }^{[6]}$ The SPA method uses an amino phase absorbent to absorb impurities within the gas, desorbs them with a solvent, and conducts an analysis and qualitative measurement using gas chromatography. It is deemed to be a suitable method for quantifying micro substances. The SPA column, however, is a specialized device, and thus it is necessary to develop a measuring method based on a more generic and readily available measuring instrument.

Meanwhile, tar content in the fuel gas that has passed through the cooling process, is comprised mostly of aromatics. In the case of these substances, it is believed that a highly-absorbable organic gas sampler can be utilized to quantify light tar. Thus, this paper examines tar measurement methods using silica gel and activated carbon tubes that offer high absorption of these aromatics. These organic gas samplers are used for measuring the concentration of VOCs in the air. An activated carbon tube provides high absorption of aromatics such as benzene, xylene, and chlorobenzene and the silica gel tube absorbs polar compounds including styrene and phenol. The manufacturer of the tubes used in the present study is Sibata Scientific Technology, Ltd. Figure 1 shows the form of the gas sampler and the sampling method. While the picture shows only the activated carbon tube, the structure of the silica gel tube is the same; the charge amounts of silica gel are $520 \mathrm{mg}$ in the front and $260 \mathrm{mg}$ in the rear. The sampling process is as follows: The silica gel and activated carbon tubes are installed in the front and rear of the sampling port, respectively. A pump is then used to ensure a certain level of suction so that the sampling gas can pass through two tubes and its tar content can be absorbed. The amount and time of suction are set at 1-2 liters and 3-5 minutes, respectively. The absorbed tar is then desorbed-using acetone for the silica gel tube and carbon disulfide for the activated carbon tube - and analyzed using the method discussed in the following section. The amount of gas suctioned is used as the basis for calculating the concentration of tar in the gas.
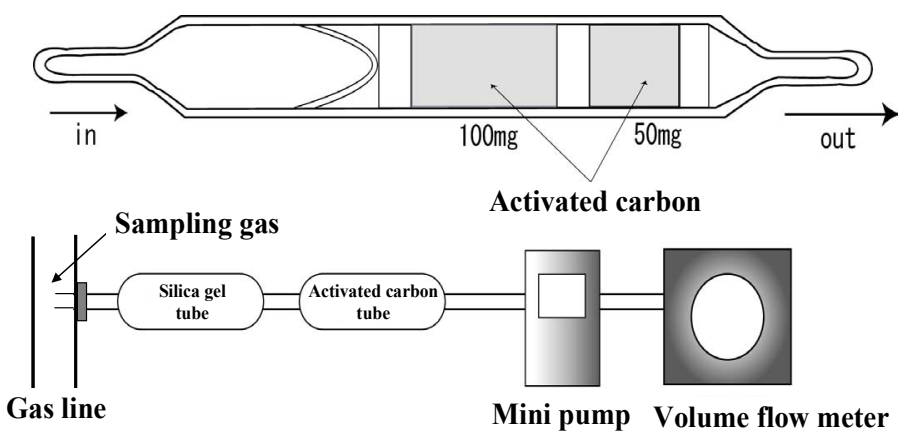

Fig. 1 Gas sampler of the form and sampling

\subsection{Analysis method}

The absorbed tar is analyzed both qualitatively and quantitatively using a gas chromatography/flame ionization detector (GC-FID). The qualitative analysis is carried out by analyzing several representative standard substances with GC-FID and using the retention time (i.e. the time taken until a substance is detected; time of peak detection) as 
the basis of estimation. The quantitative analysis is done by using the absolute measuring method, as delineated in Eq. (1).

$$
\text { Concentration }=\frac{\text { Peak area } \times \text { Correction factor }}{\text { Injection amount (To FID) }}
$$

Figure 2 shows the calibration curve of individual standard substances injected (e.g. benzene, styrene, phenol, xylenol, indene, naphthalene, acenaphthene, anthracene, and pyrene) against their peak areas (i.e. the area between the peak and baseline of each substance). With polar substances such as phenol and xylenol as exceptions, it is apparent that for other standard substances, the slope (i.e. correction factor) of the absolute amounts of test samples against their peak areas differs little by type of standard substance. Based on such results, this study devises the following quantitative method.

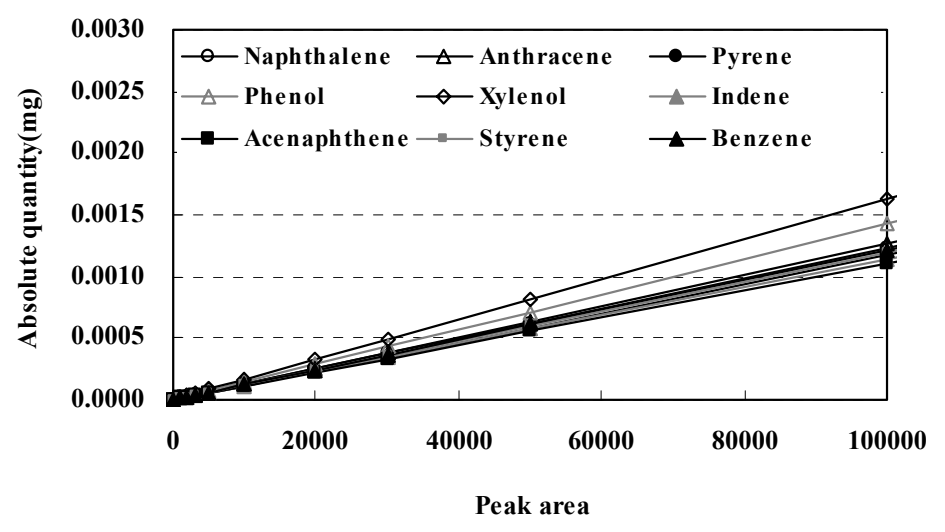

Fig. 2 Calibration curves of the standard substances

\subsection{Measuring method for light tar}

Tar contained in the waste gasification gas is a mixture of dozens to hundreds of substances, and as such it is virtually impossible to qualify and quantify all of the substances. ${ }^{[7]}$ Therefore, based on the results shown in Fig.2, this study proposes a measuring method that quantifies the entire mass of each group represented by a certain substance as shown in Table 1 instead of quantifying unspecified large number of peaks detected by GC-FID. The quantitative method uses the calibration curves shown in Fig.2; the peak area here is the sum of peak areas for each group. For substances which are identifiable, the correction factors of those substances are used to quantify them separately. Table 1 describes representative substances used in the quantitative analysis. In the chromatogram, substances are divided into four groups for quantitative analysis: Group 1 (from benzene to the substance before naphthalene), Group 2 (from naphthalene to the substance before anthracene), Group 3 (from anthracene to the substance before pyrene), and Group 4 (from pyrene to other substances detected during the retention time after pyrene).

Table 1 The representative substance used for quantitative measurement

\begin{tabular}{cc}
\hline Division & Representative substance \\
\hline \hline group 1 & Benzene \\
group 2 & Naphthalene \\
group 3 & Anthracene \\
group 4 & Pyrene \\
\hline
\end{tabular}




\section{Examination of Precision Level of Gas Sampler by Lab-scale}

\section{Gasification system}

The gas sampler used here has never been applied to the measurement of tar contents in gasification gases. Therefore, the validity and precision of this sampling method must be verified. An experiment using a lab-scale gasification system is thus conducted to investigate the precision level of the gas sampler. Figure 3 shows the schematic diagram of the laboratory experimental set-up. This process mainly consists of the feeder, pyrolyzer, reformer, tar condenser system, pretreatment system, gas analyzer, steam generator and air compressor. The pyrolyzer has dimensions of $30 \mathrm{~mm}$ for the inside diameter and $300 \mathrm{~mm}$ for the height; the reformer has $25 \mathrm{~mm}$ inside diameter and $1,300 \mathrm{~mm}$ height. Wood chips are supplied to the pyrolyzer, and tar is reformed in the reformer. The reformed gas, which flows out of the reformer, is bubbled in a water-filled impinger bottle to remove heavy tar; the gas is then sampled using the silica gel and activated carbon tubes. The sampling port and the joints to the pyrolyzer and reformer are kept at $400^{\circ} \mathrm{C}$ using a ribbon heater and temperature controller.

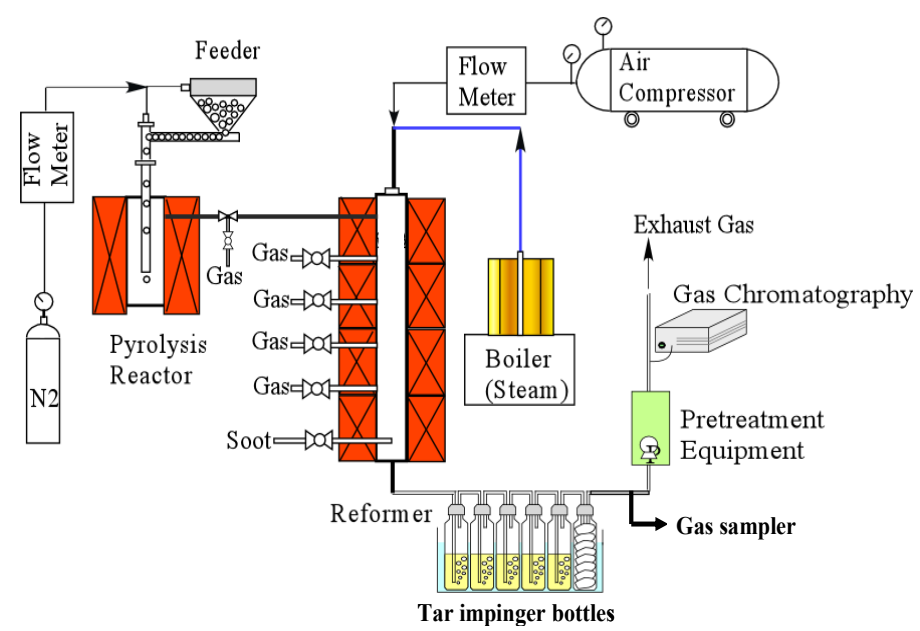

Fig. 3 Laboratory experimental set-up

\subsection{Tar components collected in the impinger bottle and the gas sampler}

Tests are conducted with the pyrolyzer and reformer set at $750^{\circ} \mathrm{C}$ and $850^{\circ} \mathrm{C}$, respectively. For the tar contained in the gas generated during the test, the concentration of each tar group collected in the impinger bottle is shown in Fig.4. The concentration of each tar group that passed through the impinger bottle and collected in the gas sampler is shown in Fig.5. For Groups 3 and 4, tar is collected mostly from bubbling in the impinger bottle, while in the case of Group 2 certain amounts of tar are collected both in the impinger bottle and the gas sampler. Therefore, the combined concentration should be used for Group 2 based on the amounts collected both in the impinger bottle and the gas sampler. Tar components with relatively higher vapor pressure in Group 1 are not collected via bubbling in the impinger bottle and pass through the impinger bottle being contained in the gas. Figure 5 shows that those substances should be collected using the gas sampler and then analyzed.

\subsection{Verification of precision level of gas sampler}

Figures 6 and 7 show the consecutive change in the concentration of light tar collected by the gas sampler when tests are conducted during the same amount of time and under the same conditions. The tar concentration of Groups 1 and 2, shown in Fig.6, remains almost constant, implying that the absorption performance of the gas sampler does not change significantly. The tar concentration around the start time of experiment is slightly low, 
which is because that the steady state is not yet to be reached. This data demonstrates that very minute change of the tar concentration in the order of $\mathrm{mg} / \mathrm{m}^{3} \mathrm{~N}$ can be measurable. As shown in Fig.7, tar components in Groups 3 and 4 undergo relatively large change. This is presumably because the absolute amounts of tar collected by the gas sampler are so small that the effects of impurities contained in the gas sampler itself or the solvent become relatively large. Also, the measured concentrations of these components change depending on the efficiency of collection in the impinger bottle, and hence this cannot be considered an accurate quantitative measurement. However, as Groups 3 and 4 are mostly removed in the cooling/gas cleaning processes in a commercial plant, this measuring method will be effective if the gas sampler is used downstream of the cooling/gas cleaning processes.

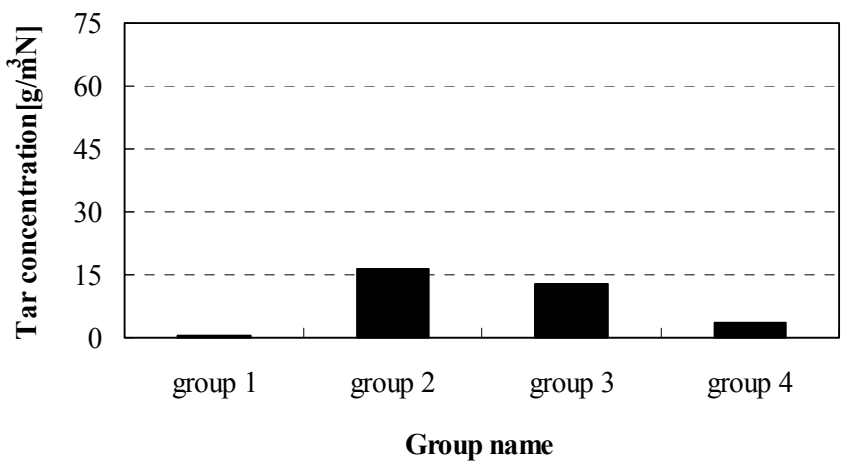

Fig. 4 Tar concentration measured by impinger collection

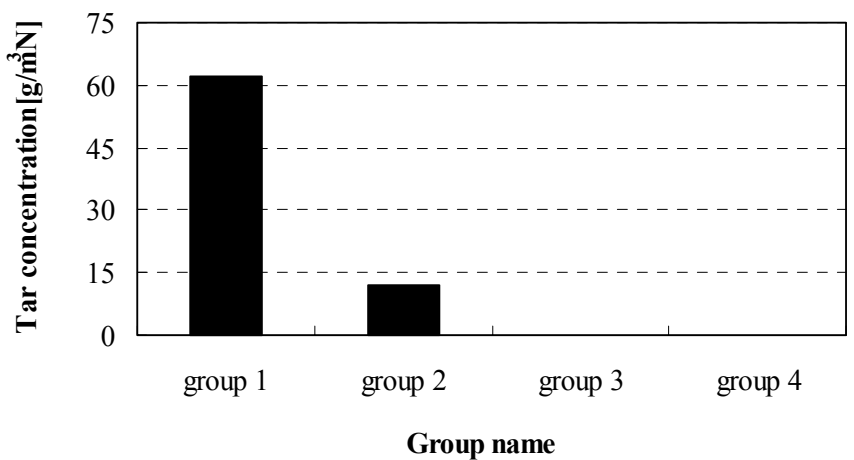

Fig. 5 Tar concentration measured by gas sampler collection

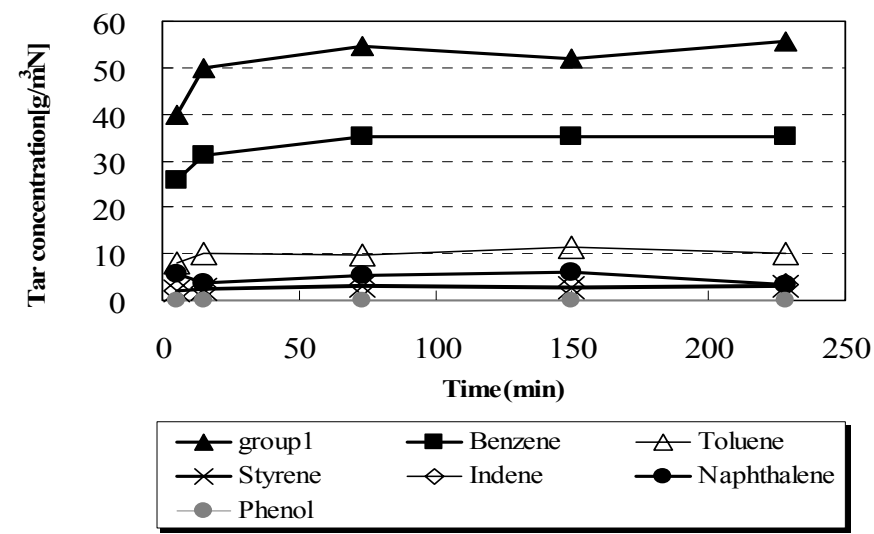

Fig. 6 Time change of the tar concentration

(Group1, Benzene, Toluene, Styrene, Indene, Phenol, Naphthalene) 


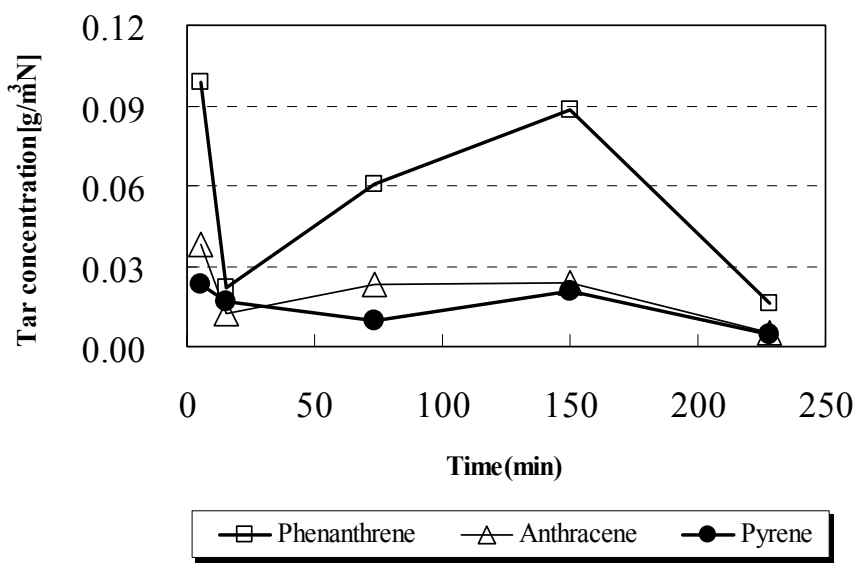

Fig. 7 Time change of the tar concentration (Phenanthrene, Anthracene, Pyrene)

Next, this gas sampler-based tar collection method is compared with the tar collection method suggested in the "Guideline for Sampling and Analysis of Tar and Particles in Biomass Producer Gases Version 3.3," prepared by six research institutions in the United States and Europe. ${ }^{[5]}$ The test is conducted with the pyrolyzer and the reformer set at $650^{\circ} \mathrm{C}$ and $800^{\circ} \mathrm{C}$, respectively. Figure 8 shows the tar sampling of Case 1 and Case2. The reformed gas flowing out of the reformer is bubbled in the water-filled impinge bottle. In Case 1, this water-washed gas passes through the gas sampler. In Case 2, isopropanol is charged in the impinger bottle as a solvent, in accordance with the guidelines, and the water-washed gas passes through this impinger bottle, whose temperature is set below $20^{\circ} \mathrm{C}$ initially and below $-20^{\circ} \mathrm{C}$ later. After the collection process is completed, the pipes are cleaned with isopropanol and this isopropanol is added to the isopropanol in the impinger bottle to be analysed. The test results are shown in Fig.9.

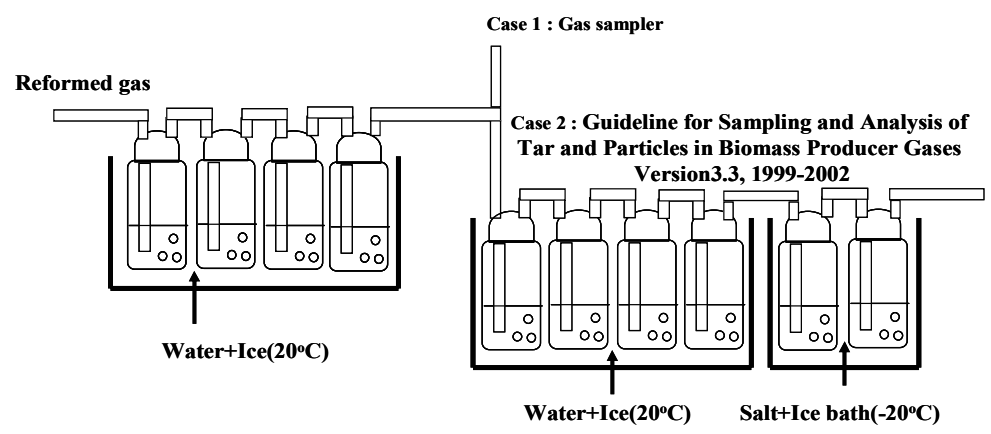

Fig. 8 Tar sampling of Case1 and Case2

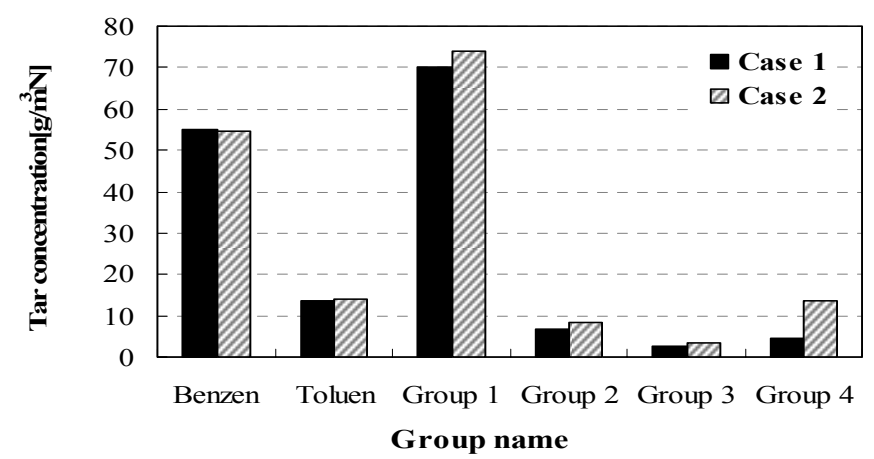

Fig. 9 Comparison of the tar concentration by Case 1 and Case2 
As shown in Fig.9, the concentrations of benzene and toluene, both of which belong to Group 1, are basically the same in Cases 1 and 2. The concentrations of each group in Case 1 differs from that in Case 2 by 5.2\% (Group 1), 19.3\% (Group 2), 26.9\% (Group 3), and $67.1 \%$ (Group 4), respectively. This is believed to be because the concentrations of Groups 3 and 4 approach the lower limit of gas sampler-based measurement. Groups 3 and 4, however, account for roughly $15 \%$ of the entire tar concentration, and hence errors in their measurement have little effect on the precision level of the overall tar concentration measurement. Furthermore, most commercial plants apply the cooling/gas cleaning processes downstream of the reforming process, and therefore most of the tar components in Groups 3 and 4, which consist mainly of substances with relatively lower vapor pressure, are removed in such cooling/gas cleaning processes. Thus, it appears that the precision level of measurement does not have a significant impact for Groups 3 and 4. In summary, regarding Groups 1 and 2, which are tar components with relatively higher vapor pressure that might flow into the engine as part of the fuel gas, the gas sampler-based measuring method suggested in this study produces nearly identical results as the method suggested in the "Guideline for Sampling and Analysis of Tar and Particles in Biomass Producer Gases Version 3.3" which are applied in Case 2. Therefore, the proposed method in this paper is considered valid as a light tar measuring method that is conveniently used in a short period of time for a commercial plant.

\section{Analysis of Light Tar Components in a Commercial Plant}

Using the foregoing methods, the concentration of tar is measured at the commercial plant mentioned above. In this operation, the amounts of fuel supplied in a single time band, for the sampling of light tar, are $600 \mathrm{~kg}$ in total: $300 \mathrm{~kg} / \mathrm{h}$ for meat and bone meal, $200 \mathrm{~kg} / \mathrm{h}$ for municipal solid waste (MSW), and $100 \mathrm{~kg} / \mathrm{h}$ for wood chips. The sampling of light tar and measurement of gas composition are performed at the outlet of the gas holder, installed upstream of the power generator, for five hours. Figure 10 shows the time change of the low heating value (LHV) of the fuel gas. The gasifier should form a gradually-descending temperature distribution: high temperature around $900{ }^{\circ} \mathrm{C}$ down to low temperature of approximately $300{ }^{\circ} \mathrm{C}$ from the lower part to the upper part of the gasifier. During the first two hours, the gasifier temperature is low, and the intended distribution of temperature descending from the lower part to the upper part is not formed. As a result, there is a significant fluctuation of LHV in this period. During the last three hours, the intended temperature distribution is observed, showing LHV value of the fuel gas remains relatively stable. In a commercial plant, the cooling/gas cleaning process is applied downstream of the reforming process, and thus the amounts of tar contents are limited. For this reason, tar components belonging to Groups 3 and 4 are not found in this test. Figure 11 shows changes in the concentration of benzene, styrene, phenol, and indene; Figure 12 shows changes in the concentration of Group 2 and naphthalene. The concentrations of tar in the fuel gas shown in these figures are lower than that of each component discussed in Section 3, as the fuel gas is diluted by nitrogen in the high-temperature air injected during the gasification/reforming process. Figure 11 indicates that approximately $0.1 \mathrm{~g} / \mathrm{m}^{3} \mathrm{~N}$ of phenol, a corrosive substance, is contained and that the amounts of benzene contained here are especially large. There has been no report, however, that the inflow of benzene has a particularly negative impact on the engine; some studies have not even defined benzene as $\operatorname{tar}^{[7]}$ The results of Figure 12 indicate that approximately $0.28 \mathrm{~g} / \mathrm{m}^{3} \mathrm{~N}$ of naphthalene, a substance that is solidified at normal temperature, is contained. Condensates on the turbocharger impeller and other devices are analyzed on this basis, and light tar-presumably around $30 \%$ of the whole mass of the condensates — is highly likely to be a compound whose main component is naphthalene. 


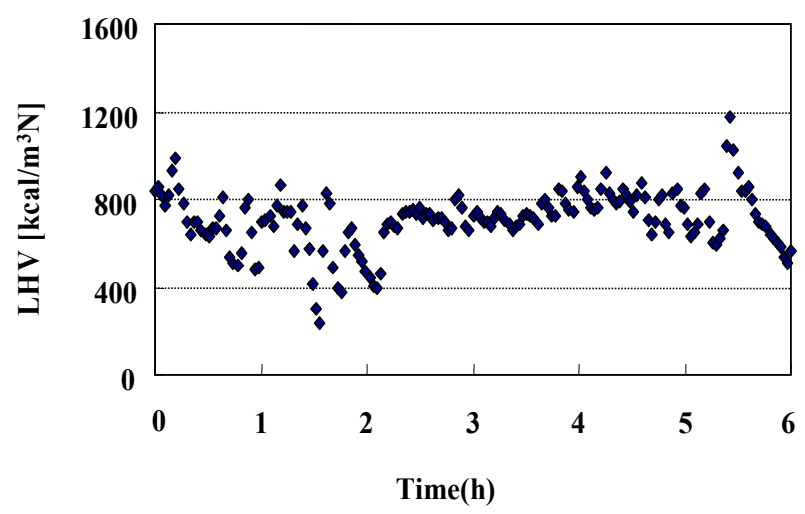

Fig. 10 Time change of the fuel gas LHV

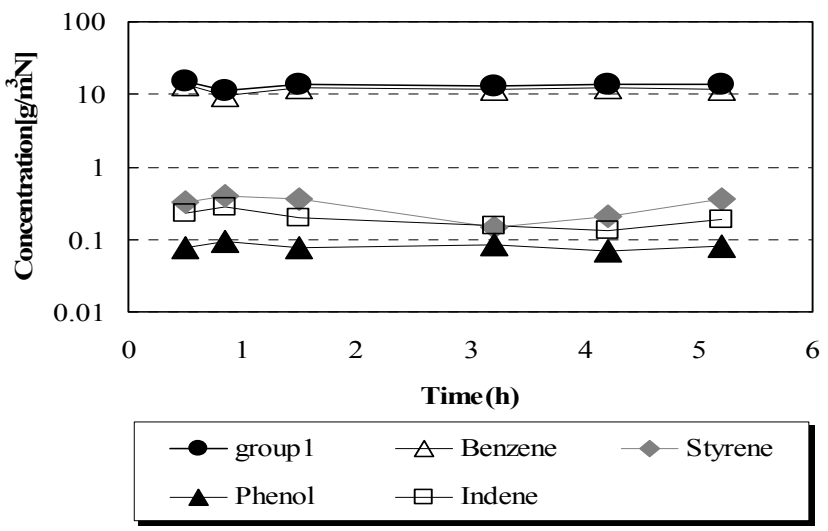

Fig. 11 Time change of the tar concentration (group1, Benzene, Styrene, Phenol, Indene)

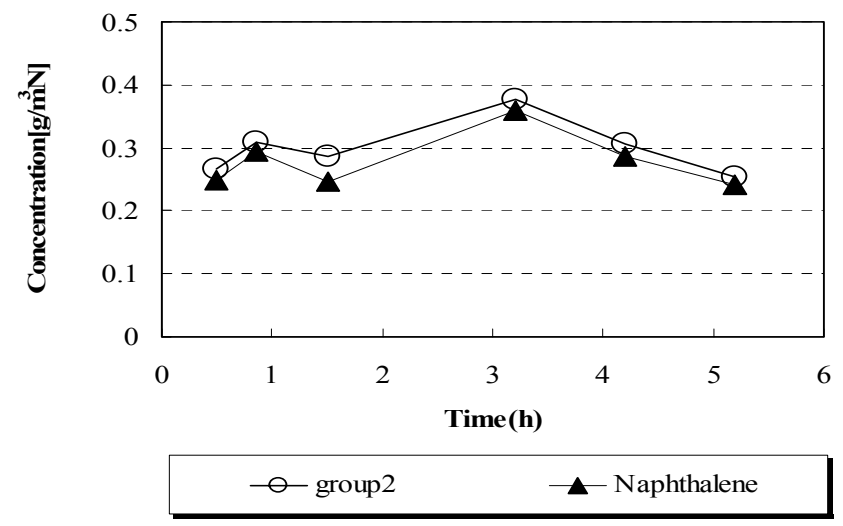

Fig. 12 Time change of the tar concentration (group2, Naphthalene) 


\section{Possibility of Filter-Based Removal of Light Tar}

Based on the above results, certain amounts of light tar components may be remained in the fuel gas even after passing through the reforming and cooling/gas cleaning processes. Therefore, in this section, effects of physical removal of such light tar components by sawdust and activated carbon filters are investigated in the lab-scale gasification system test (RUN1; wood chips used for the test) and in the operation of a commercial plant (RUN2). RUN1 is a simulation test on light tar removal using the gasification system described in Section 3 and the experimental conditions are presented in Table 2. The same volumes of sawdust and activated carbon are charged into impinger bottles, and light tar is measured by absorption using the gas sampler located upstream and downstream of the filters (i.e. sawdust and activated carbon filters). Sawdust has a particle size of $0.5-1.0 \mathrm{~mm}$; activated carbon (manufactured by Kanto Chemical Co.) has a granular form with a particle size of $3.35-4.75 \mathrm{~mm}$. The residence time of gas within the filter is 4.6 seconds for sawdust and 4.2 seconds for activated carbon. For sawdust, large sawdust particles are packed on the upper part of the sawdust bed in order to promote gas dispersion. The charged amount is $300 \mathrm{ml}$ for both activated carbon and sawdust.

Table 2 Experimental conditions

\begin{tabular}{c|c|c|c}
\hline $\begin{array}{c}\text { Feed rate of } \\
\text { wood chips }\end{array}$ & $\begin{array}{c}\text { Flow rate } \\
\text { of } \mathrm{N}_{2}\end{array}$ & $\begin{array}{c}\text { Pyrolyzer } \\
\text { temperature }\end{array}$ & $\begin{array}{c}\text { Reformer } \\
\text { temperature }\end{array}$ \\
\hline \hline $1.0 \mathrm{~g} / \mathrm{min}$ & $2.0 \mathrm{~L} / \mathrm{min}$ & $750^{\circ} \mathrm{C}$ & $850^{\circ} \mathrm{C}$ \\
\hline
\end{tabular}

The collection efficiency defined by the Eq. (2) is applied to compare the tar filtering performance of sawdust and activated carbon.

Tar concentration at the filter inlet - Tar concentration at the filter exit

$$
\text { Tar concentration at the filter inlet }
$$

Table 3 shows the collection efficiency of light tar components in RUN1. The amounts of gas passing through are the net amounts of gas generated, excluding carrier gas. The results of a lab-scale gasification system test (RUN1) show that most of the components are collected very efficiently after being filtered by activated carbon. In the case of sawdust, indene is the only component with the collection efficiency exceeding $90 \%$ in Group 1, while other tar components in this group show low collection efficiency. Meanwhile, sawdust shows the same filtering performance as activated carbon to absorb substances that might become solidified at normal temperature and form condensates within the pipes or the engine (e.g. naphthalene and phenanthrene). Figure 13 shows changes in sawdust's collection efficiency of styrene (Group 1), indene (Group 1), naphthalene (Group 2), and phenanthrene (Group 3) against cumulative passed gas volume flow (per unit mass of sawdust). The cumulative volume flow of gas passage are the net cumulative volume flow of gas passing through, that is the volume flow of gas measured minus those of the carrier gas. For components belonging to Groups 1 and 2, their collection efficiency declines as the cumulative volume flow of gas passage increases. This is presumed to be because, with increase in cumulative volume flow of gas passage, the amount of tar absorbed on sawdust increases, which results in decrease of the absorption capacity of tar within the gas. Also, when $1 \mathrm{~g}$ of sawdust is used to absorb $0.0423 \mathrm{~g}$ of light tar (benzene and toluene excluded), the collection efficiency drops by around $20 \%$. If the tar concentration of a commercial plant $\left(0.95 \mathrm{~g} / \mathrm{m}^{3} \mathrm{~N}\right.$; benzene and toluene excluded) is applied to this calculation, the collection efficiency declines by $20 \%$ when tar is absorbed for an hour with $45 \mathrm{~kg}$ of sawdust, where the volume flow rate of fuel gas is assumed to be $2,000 \mathrm{~m}^{3} \mathrm{~N} / \mathrm{h}$. 
Table 3 Tar concentration and collection efficiency in RUN1

\begin{tabular}{|c|c|c|c|c|c|c|}
\hline \multicolumn{7}{|c|}{ RUN1 } \\
\hline \multirow[b]{2}{*}{ Component } & \multicolumn{3}{|c|}{ Sawdust filter } & \multicolumn{3}{|c|}{ Activated carbon filter } \\
\hline & $\begin{array}{c}\text { Filter inlet } \\
{\left[\mathrm{g} / \mathrm{m}^{3} \mathrm{~N}\right]}\end{array}$ & $\begin{array}{l}\text { Filter exit } \\
{\left[\mathrm{g} / \mathrm{m}^{3} \mathrm{~N}\right]}\end{array}$ & $\begin{array}{c}\text { Collection } \\
\text { efficiency[\%] }\end{array}$ & $\begin{array}{l}\text { Filter inlet } \\
{\left[\mathrm{g} / \mathrm{m}^{3} \mathrm{~N}\right]}\end{array}$ & $\begin{array}{l}\text { Filter exit } \\
{\left[\mathrm{g} / \mathrm{m}^{3} \mathrm{~N}\right]}\end{array}$ & $\begin{array}{c}\text { Collection } \\
\text { efficiency[\%] }\end{array}$ \\
\hline Benzene & 35.14 & 33.14 & 5.7 & 35.14 & 0 & 100 \\
\hline Toluene & 9.86 & 9.32 & 5.5 & 9.86 & 0 & 100 \\
\hline Xylene & 0.84 & 0.58 & 31.0 & 0.84 & 0 & 100 \\
\hline Styrene & 2.95 & 1.56 & 47.1 & 2.95 & 0.003 & 99.9 \\
\hline Phenol & 0.11 & 0.08 & 27.3 & 0.11 & 0 & 100 \\
\hline Indene & 3.32 & 0.24 & 92.8 & 3.32 & 0.021 & 99.4 \\
\hline Naphthalene & 5.52 & 0.066 & 98.8 & 5.52 & 0.074 & 98.7 \\
\hline Phenanthrene & 0.06 & 0.003 & 95.0 & 0.06 & 0 & 100 \\
\hline Anthracene & 0.023 & 0 & 100.0 & 0.023 & 0.005 & 78.3 \\
\hline Pyrene & 0.009 & 0.002 & 77.8 & 0.009 & 0.004 & 55.6 \\
\hline
\end{tabular}

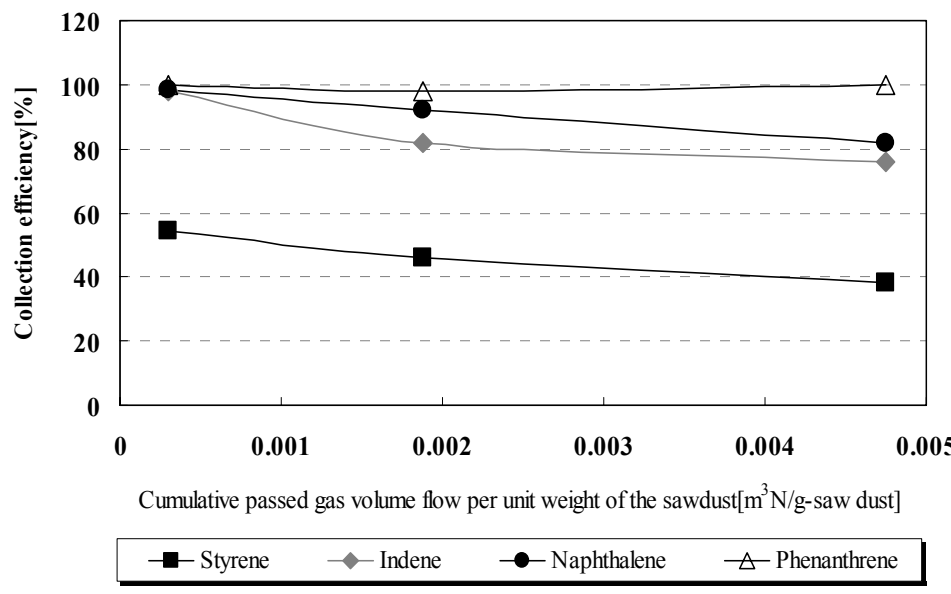

Fig.13 Collection efficiency as a function of the cumulative passed gas volume flow

Considering the results of RUN1, it is apparent that activated carbon is a suitable filtering material for removing light tar. For a commercial plant, where naphthalene is highly likely to be the main component of condensates within the engine, it is believed sawdust may also be used as a filter. As the commercial plant uses wood chips as part of their gasification fuel, one advantage of the usage of sawdust is that after its use as a filter is finished, it can then be disposed of as fuel. Thus, tar components are measured by charging sawdust within the gas holder of a commercial plant and letting fuel gas pass through it (RUN2). In this operation, the amount of fuel supplied in a single time band, for the sampling of light tar, is $600 \mathrm{~kg}$ in total: $200 \mathrm{~kg} / \mathrm{h}$ for meat and bone meals, $200 \mathrm{~kg} / \mathrm{h}$ for municipal solid waste (MSW), and $200 \mathrm{~kg} / \mathrm{h}$ for wood chips. The results of measurement are shown in Table 4. The measurement results show that naphthalene, a substance that is of concern for the commercial plant, can be removed by sawdust with a collection efficiency of over $98 \%$. 
Table 4 Tar concentration and collection efficiency in RUN2

\begin{tabular}{|c|c|c|c|}
\hline \multicolumn{4}{|c|}{ RUN2 } \\
\hline Component & Gas holder inlet $\left[\mathrm{g} / \mathrm{m}^{3} \mathrm{~N}\right]$ & Gas holder exit $\left[\mathrm{g} / \mathrm{m}^{3} \mathrm{~N}\right]$ & Collection efficiency[\%] \\
\hline Benzene & 3.95 & 3.59 & 9.1 \\
\hline Toluene & 0.067 & 0.049 & 26.9 \\
\hline Xylene & 0.016 & 0.004 & 75.0 \\
\hline Styrene & 0.034 & 0.008 & 76.5 \\
\hline Phenol & 0.021 & 0.003 & 85.7 \\
\hline Indene & 0.036 & 0.002 & 94.4 \\
\hline Naphthalene & 0.340 & 0.006 & 98.2 \\
\hline Phenanthrene & 0.015 & 0.0025 & 83.3 \\
\hline Anthracene & 0.006 & 0.0012 & 80.0 \\
\hline Pyrene & 0.0039 & 0.0013 & 66.7 \\
\hline
\end{tabular}

\section{Conclusions}

This study has suggested methods for measuring light tar in a short period of time at a waste gasification power generation plant, and at the same time, examined methods for analyzing and reducing small amount of light-weight tar (light tar) in a gasification power generation plant. On this basis, this study has reached the following conclusions:

- For Groups 1 and 2, which are tar components with relatively higher vapor pressure that might flow into the engine as part of the fuel gas, the measuring method using the activated carbon and silica gel tubes-organic gas samples used in measuring the concentration of VOCs - shows nearly identical results to those obtained from the method suggested in the "Guideline for Sampling and Analysis of Tar and Particles in Biomass Producer Gases Version 3.3." Thus, the method is found to be valid as a light tar measuring method that is conveniently applied in a short period of time to commercial plants.

- This study has shown that reforming or cooling/gas cleaning process alone is not enough to rule out the possibility that naphthalene, phenanthrene, pyrene, and other substances that are solidified at normal temperature might remain in the fuel gas. The condensates on the turbocharger impeller and other parts within the engine observed in the commercial plant are highly likely to be compounds of light tar-consisting mainly of ammonium chloride and naphthalene and including small amounts of phenol and other corrosive substances - and small amount of heavy tar.

- In removal light tar, activated carbon shows a higher efficiency of collection than sawdust. In the case of removal of naphthalene, a substance of concern in commercial plants, this study has found that sawdust can also be used as a filter. 


\section{References}

(1) Y.I, Son. et al., A study on a Small-scale Gasification and Power Generation from Municipal Solid Wastes and Biomass Fuels, Transactions of the Japan Society of Mechanical Engineers, Series B,Vol.72,No.722(2006), pp.2367-2374

(2) BTG Biomass Technology Group, Cleaning of Hot Producer Gas in a Catalytic, Reverse Flow Reactor, Final Report(1995), EWAB 9605, NOVEM

(3) Baker, E.G. et al., Engineering Analysis of Biomass Gasifier Product Gas Cleaning Technology, Biofuels and Municipal Waste Technology Division(1986), PNL-5534

(4) Bui, T. et al., Multi-Stage Reactor for Thermal Gasification of Wood, Energy 19(1994), pp.397-404

(5) Guideline for Sampling and Analysis of Tar and Particles in Biomass Producer Gases Version3.3(1999-2002)

(6) Brage, et al.,Use of amino phase adsorbent for biomass tar sampling and separation ,Fuel, Volume 76, Issue 2(1997), pp.137-142

(7) Nick Abatzoglou, Nick Barker., The development of a draft protocol for the sampling and analysis of particulate and organic contaminants in the gas from small biomass gasifiers, Biomass and Bioenegy 18(2000), pp.5-17 